\title{
WELL-DIFFERENTIATED LIPOSARCOMA OF THE LARYNX: A CASE REPORT AND REVIEW OF LITERATURE
}

\author{
Svetlana A. Mateva, \\ Margarita R. Nikolova, \\ Alexandar V. Valkov', \\ Julia M. Todorova-Doneva ${ }^{1}$ \\ Department of Patholoanatomy, \\ Faculty of Medicine, \\ Medical University - Pleven \\ ${ }^{1}$ Department of Otolaryngology, \\ Faculty of Medicine, \\ Medical University - Pleven
}

\section{Corresponding Author:}

Margarita R. Nikolova

Department of Patholoanatomy,

Medical University - Pleven

1, St. Kliment Ohridski Str.

Pleven, 5800

Bulgaria

e-mail:mnikol@abv.bg

Received: June 23, 2016

Revision received: August 25, 2016

Accepted: September 15, 2016

\begin{abstract}
Summary
Liposarcoma is one of the most common soft tissue sarcomas in adults with a relative incidence amongst other sarcomas ranging from $9.8 \%$ to $16 \%$. It usually locates in the limbs and retroperitoneum. Primary liposarcomas of the larynx and hypopharynx are rare, comprising less than $20 \%$ of all head and neck liposarcomas. According to World Health Organization, these tumors are divided into four histologic types, and well-differentiated liposarcoma is the most common one. It is a tumor of low-grade malignancy that may recur locally, but does not metastasize. We present a case of laryngopharyngeal welldifferentiated liposarcoma in an old patient with two previous removals. We also discuss recently published cases with this unusual location of liposarcoma.
\end{abstract}

Key words: liposarcoma, larynx, well-differentiated

\section{Introduction}

Liposarcoma is one of the most common soft tissue sarcomas in adult life with a relative incidence amongst other sarcomas ranging from $9.8 \%$ to $16 \%$. It ranges widely in structure and behavior from nonmetastasizing neoplasm to high-grade sarcoma with full metastatic potential [1]. The World Health Organization (WHO) divides liposarcomas into four types: atypical lipomatous tumor (ALT)/welldifferentiated liposarcoma (WLS), myxoid/round cell liposarcoma (MLS), dedifferentiated liposarcoma (DLS) and pleomorphic liposarcoma (PLS). The most common type is WLS that accounts for about $40-45 \%$ of all liposarcomas. It occurs frequently in deep soft tissues of the limbs, followed by the retroperitoneum. It can be further subdivided into four main subtypes: adipocytic (lipoma-like), sclerosing, inflammatory, and spindle cell [2]. Primary liposarcomas of the larynx and hypopharynx are rare, comprising less than $20 \%$ of all head and neck liposarcomas and less than $0.5 \%$ of all laryngeal neoplasms. There is a marked male to female predominance (nearly 10:1). The majority of cases are WLS with infrequent reports of MLS and PLS [3]. We present a case of laryngopharyngeal WLS in a male patient with two previous endoscopic removals. 


\section{Case Report}

An 85-year-old man presented to the Ear, Nose and Throat Clinic with complaints of progressive dysphagia to liquid and gruel food along with slight dyspnea. Four years before he had presented to the same clinic with severe dyspnea and dysphagia. The symptoms were caused by a lipoma measuring 5-6 cm in diameter located in the left recessus piriformis, closing the esophageal ostium and pushing the larynx. Lateral pharyngotomy was performed and the tumor was excised. A year later, the patient was admitted to the clinic again, complaining of dysphagia. A pedunculated tumor measuring $3 / 2$ $\mathrm{cm}$ was found attached to the left valecula. Using microlaryngosurgery the tumor was totally removed and histological examination revealed differentiated liposarcoma. At present, indirect laryngoscopy revealed a tumor with lobulated surface, involving the left recessus piriformis and obturating the esophageal and laryngeal ostia. After direct laryngoscopy and CT contrast examination, laryngectomy was performed. Gross examination of the resected larynx showed a soft, yellow, smooth-surfaced tumor involving left aryepiglotic fold, left and right recessus piriformis, penetrating to left false vocal cord and sinus of Morgani and closing the esophageal ostium. The tumor was yellow in color and lobulated on cut surface, well-circumscribed (Figure 1). Histologically, it was covered by intact mucosa on one side and showed lobular arrangement (Figure 2). The tumor consisted mainly of mature adipocytes of varying size, some of them with hyperchromatic nuclei. Univacuolar and multivacuolar lipoblasts were easily identifiable (Figure 3). Mitotic activity was very low and pathological mitoses and necroses were absent. The tumor cells were diffusely positive for vimentin and S-100. Ki67 showed positivity in less than $5 \%$ of tumor cells. Based on the typical macro- and microscopic appearance of the tumor, supported by immunohistochemical examination, the diagnosis made was well-differentiated liposarcoma, lipoma-like subtype. The patient made a full recovery and was discharged on the eleventh postoperative day.

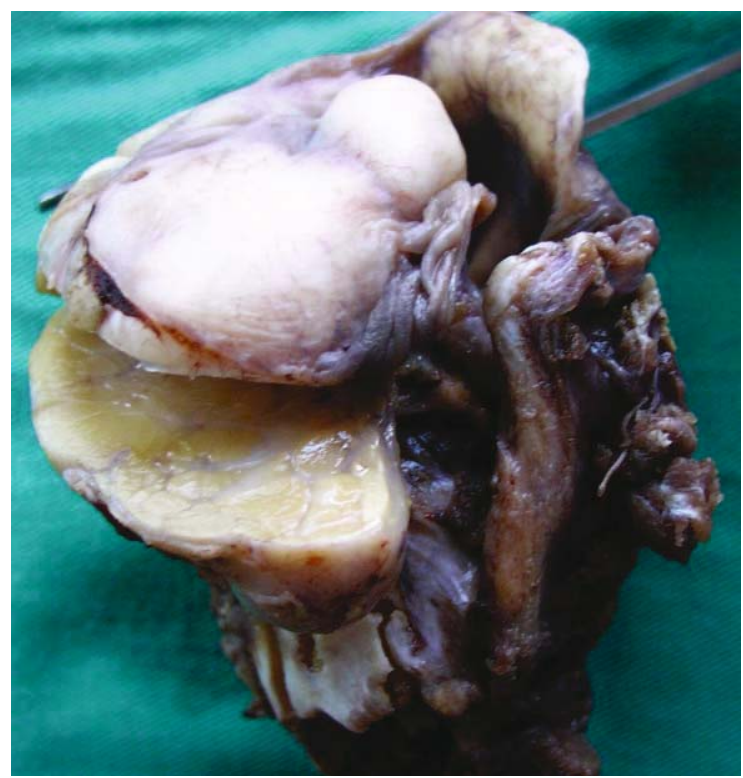

Figure 1. Smooth-surfaced, well-circumscribed tumor involving left aryepiglotic fold, left and right recessus piriformis, closing esophageal ostium. Cut surface is yellow in color and lobulated

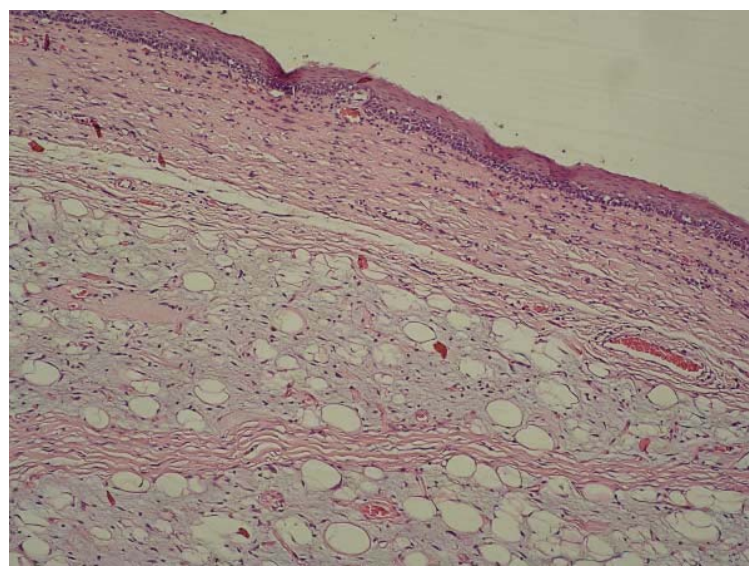

Figure 2. The tumor is covered by intact mucosa on one side and showed lobular arrangement

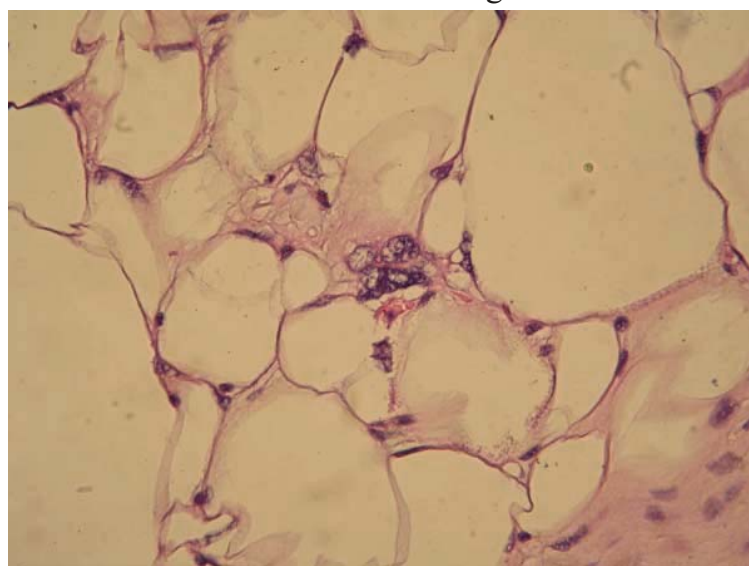

Figure 3. The tumor consists mainly of mature adipocytes of varying size, some of them with hyperchromatic nuclei. Univacuolar and multivacuolar lipoblasts are easily identifiable 


\section{Discussion}

Liposarcomas of the larynx and hypopharynx are very rare. We found 48 cases reported so far in the literature published in English, 3 cases - in Spanish [4-6], 2 cases - in French [7, 8], and 1 case - in German [9]. The first case of laryngeal liposarcoma was reported by Miller in 1976 [10].
The largest series of laryngopharyngeal liposarcomas were reported by Wenig et al. in 1990 (10 cases), and in 1995 other 8 cases were reported, WLS being the most common variant [8, 11-14]. Other variants of liposarcoma such as MLS $[4,15,16]$ and DLS $[9,17-21]$ have rarely been seen in the larynx and pharynx. All reports are listed in Table 1.

Table1. Review of studies on liposarcomas of larynx and hipopharynx

\begin{tabular}{|c|c|c|}
\hline Reference & Larynx 31 cases & Hypopharynx 23 cases \\
\hline Muddaiah A. et al. [22] 2010 & $1 \mathrm{WLS}$ & - \\
\hline Mestre de Juan M.J. et al. [23] 1999 & $1 \mathrm{WLS}$ & - \\
\hline Gleinser D.M. et al. [15] 2010 & $1 \mathrm{MLS}$ & - \\
\hline Shi H. et al. [11] 2010 & 3 ALT/WLS & 2 ALT/WLS \\
\hline Brauchle R.W. et al. [24] 2001 & $1 \mathrm{WLS}$ & - \\
\hline Fahmy F.F. et al. [25] 1998 & - & $1 \mathrm{WLS}$ \\
\hline Powitzky R. et al. [26] 2007 & $1 \mathrm{LS}$ & - \\
\hline Wambeek N.D. et al. [27] 1996 & - & $1 \mathrm{WLS}$ \\
\hline Wenig B.M. et al. [13] 1995 & $6 \mathrm{LS}$ & $2 \mathrm{WLS}$ \\
\hline Wenig B.M. et al. [14] 1990 & $6 \mathrm{WLS}$ & $4 \mathrm{WLS}$ \\
\hline Makeief M. et al. [17] 2010 & $1 \mathrm{DLS}$ & - \\
\hline Mandell D.L. et al. [12] 1999 & - & $1 \mathrm{WLS}$ \\
\hline El Ouakif F. et al. [7] 2011 & - & $2 \mathrm{WLS}$ \\
\hline Mouret P. [28] 1999 & - & $1 \mathrm{WLS}$ \\
\hline Nouri H. et al. [29] 2011 & - & $1 \mathrm{WLS}$ \\
\hline Sotirović J. et al. [30] 2014 & - & $1 \mathrm{WLS}$ \\
\hline Nishihoria T. et al. [31] 2011 & - & 1WLS \\
\hline Luna-Ortiz K. et al. [16] 2009 & - & $1 \mathrm{MLS}$ \\
\hline Giordano G. et al. [18] 2006 & - & $1 \mathrm{DLS}$ \\
\hline Hurtado J.F. et al. [32] 1994 & $1 \mathrm{WLS}$ & - \\
\hline Reed J.M. et al. [33] 1996 & - & $1 \mathrm{WLS}$ \\
\hline Miller D. et al. [10] 1976 & $1 \mathrm{LS}$ & - \\
\hline Sanz Gonzalo J.J. et al. [4] 2002 & - & $1 \mathrm{MLS}$ \\
\hline Almela Cortés R. et al. [5] 2002 & $1 \mathrm{LS}$ & - \\
\hline Meis J.M. et al. [34] 1986 & $1 \mathrm{WLS}$ & - \\
\hline Allsbrook W.C. Jr. et al. [35] 1985 & $1 \mathrm{LS}$ & - \\
\hline Pérez González R. et al. [6] 2013 & $1 \mathrm{LS}$ & - \\
\hline Acharki A. et al. [8] 1989 & $1 \mathrm{LS}$ & - \\
\hline Steiger P. et al. [9] 1992 & $1 \mathrm{DLS}$ & - \\
\hline Gonzales-Lois C. et al. [19] 2002 & - & $1 \mathrm{DLS}$ \\
\hline Tobey D.N. et al. [20] 1979 & $1 \mathrm{DLS}$ & - \\
\hline McCormick D. et al. [21] 1994 & $1 \mathrm{DLS}$ & - \\
\hline Takano K. et al. [36] 2011 & - & $1 \mathrm{WLS}$ \\
\hline
\end{tabular}

Abbreviations: WLS - well-differentiated liposarcoma; MLS - myxoid/round cell liposarcoma; ALT/WLS atypical lipomatous tumor/well-differentiated liposarcoma; LS - liposarcoma; DLS - dedifferentiated liposarcoma 
WLS of the larynx and hypopharynx occurs almost exclusively in adults, usually in older age groups in the fifth to the eighth decades of life [14, 37]. There is a marked male to female predominance [3, 8, 13, 14, 37]. Most of the tumors are polypoid, usually lobulated and glistening, covered by intact mucosa, with the most frequent histological appearance of lipomalike subtype [3, 11-14]. The most common symptoms are dysphagia and dyspnea [3, 12-14].

Although most cases of WLS can be diagnosed microscopically based on $\mathrm{H} \& \mathrm{E}$ sections, sometimes it may be difficult to rule out lipoma [11, 30]. Histological appearance within WLS may vary and areas of well-differentiated adipocytes can be seen. This suggests wide histological sampling and immunohistochemical staining. Both lipomas and WLS are permanently labeled with vimentin and D-100 proteins, but murine double minute 2 (MDM-2) and cyclindependent kinase 4 (CDK-4) are diffusely or focally positive in tumor cells of WLS and negative in lipoma, so they may be useful in differential diagnosis [11, 30, 37]. In recently published literature, WLS is characterized by 12q13-15 amplification; this genomic segment includes genes such as MDM-2 [37].

In spite of surgical treatment of laringopharyngeal WLS, multiple recurrences are common ( $80 \%$ of cases) $[3,13,14,22,30,31]$ with an average of 69 months between excision and recurrence $[25,33]$. The recurrent tumor may differ histologically from the primary tumor [30].

Complete removal by wide excision is essential in treating liposarcoma of all locations, and most WLS of the larynx and hypopharynx can be cured. However, incomplete excision of the tumor may result in local recurrence [11, 30, 31]. For anatomical reasons, the extensiveness of surgery for laringopharyngeal tumors is usually restricted to some extent and surgical margins are relatively close to the tumor. Thus pharyngolaryngectomy with supplementary laser resection is the optimal choice for laryngopharyngeal WLS in order to remove the tumor as completely as possible $[11,13,16]$. Difficulties in evaluating the surgical margins are common after laser surgery and fragmentation of the tumor, and this is one serious disadvantage of laser surgery $[16,31]$. Long term follow-up is necessary $[30,31]$. There are controversial opinions on postoperative radiation therapy, although it may be beneficial, especially after excision of WLS recurrence [16, 23]. The risk of lymph node or distant metastasis is very low, so neck dissection is not indicated $[13,14]$.

\section{Conclusions}

Most WLS of laryngopharyngeal region can be cured by complete excision. The completeness of excision must be evaluated by wide sampling of tumor margins. Careful and wide sampling of the tumor is basic for diagnosing WLS lipoma-like subtype. In some equivocal cases, immunohistochemical staining with MDM-2 and CDK-4 is helpful. Because of the high recurrence rate of laryngopharyngeal liposarcomas, long term follow-up is necessary.

\section{References}

1. Weiss SW, Goldblum JR. Liposarcoma. In: Weiss SW, Goldblum JR, editors. Enzinger and Weiss's soft tissue tumors. 5th ed. St. Louis: Mosby; 2007. p. 641-65.

2. Fletcher CDM, Unni KK, Mertens F, editors. World Health Organization classification of tumours. Pathology and genetics of tumours of soft tissue and bone. Lyon: IARC Press; 2002.

3. Barnes L, Eveson LW, Reichard P, Sidransky D, editors. World Health Organization classification of tumours. Pathology and genetics of head and neck tumours. Lyon: IARC Press; 2005.

4. Sanz Gonzalo JJ, P. Martinez Molina P, Ribalta Farres MT, Sabater Matadelabarata F. Liposarcoma of the hypopharynx. Acta Otorrinolaryngol Esp. 2002;53(1):60-3.

5. Almela Cortŭs R, Moreno Carazo A, Martнn Rodruguez L. Laryngeal and hypopharyngeal liposarcoma. Report of a case and literature review. An Otorrinolaringol Ibero Am. 2002;29(5):431-8.

6. Pérez González R, Martín Sigüenza G, Alonso Orcajo N, Casas Rubio C. Sarcoma of the larynx. Report of two cases. An Otorrinolaringol Ibero Am. 2003;30(3):301-13.

7. El Ouakif F, Decourselle F, Schultheis D. Liposarcoma of the hypopharynx: two case reports and literature review. Rev Laryngol Otol Rhinol (Bord). 2011;132(4-5):245-50.

8. Acharki A, Sahraoui S, Benider A, Samlali R, Kahlain A. Liposarcoma of the larynx. Review of the literature apropos of a case. Cancer Radiother. 1999;3(3):245-8.

9. Steiger P, Maurer R, Honegger HP. Liposarcoma of the laryngeal region. Case report and literature review. Schweiz Med Wochenschr. 1992;122(24):944-9.

10. Miller D, Goodman M, Weber A, Goldstein A. Primary liposarcoma of the larynx. Trans Am Acad Ophthalmol Otolaryngol. 1976;82:569-70. 
11. Shi H, Wei L, Wang H, Sun L. Clinicopathological features of atypical lipomatous tumors of the laryngopharynx. J Zhejiang Univ Sci B. 2010;11(12):918-22.

12. Mandell DL, Brandwein MS, Woo P, Som PM, Biller HF, Urken ML.. Upper aerodigestive tract liposarcoma: report on four cases and literature review. Laryngoscope. 1999;109(8):1245-52.

13. Wenig BM, Heffner DK. Liposarcomas of the larynx and hypopharynx: a clinicopathologic study of eight new cases and a review of the literature. Laryngoscope. 1995;105(7 Pt 1):74756.

14. Wenig BM, Weiss SW, Gnepp DR. Laryngeal and hypopharyngeal liposarcoma. A clinicopathologic study of 10 cases with a comparison to soft-tissue counterparts. Am J Surg Pathol. 1990;14(2):13441.

15. Gleinser DM, Font JP, Clement CG, Mohammed BS, Underbrink MP. Primary myxoid liposarcoma of the supraglottic larynx. Rare Tumors. 2010;2(3):112-4.

16. Luna-Ortiz K, Campos-Ramos E, Carmona-Luna T, Mohar-BetancourtA, Ferrari-Carballo T. Laser resection of liposarcoma of the hypopharynx. Med Oral Patol Oral Cir Bucal. 2009;14(5):E252-6.

17. Makeief M, Pelliccia P, Poizat F, Arnaud S, Rat F, Cuppissol D, et al. Laryngeal dedifferentiated liposarcoma. Eur Arch Otorhinolaryngol. 2010; 267(6):991-4.

18. Giordano G, Corcione L, Gnetti L, Mercante G, Ferri T. Dedifferentiated liposarcoma of the pyriform sinus. Oral Oncol. 2006;42(4):176-80.

19. Gonzalez-Lois C, Ibarrola C, Ballestin C, Martanez-Tello FJ. Dedifferentiated liposarcoma of the pyriform sinus: report of a case and review of the literature. Int J Surg Pathol. 2002;10(1):75-9.

20. Tobey DN, Wheelis RF, Yarington Jr CT. Electron microscopy in the diagnosis of liposarcoma and fibrosarcoma of the larynx. Ann Otol Rhinol Laryngol. 1979;88(Pt 1):867-71.

21. McCormick D, Mentzel T, Beham A, Fletcher CD. Dedifferentiated liposarcoma. Clinicopathologic analysis of 32 cases suggesting a better prognostic subgroup among pleomorphic sarcomas. Am J Surg Pathol. 1994;18(12):1213-23.

22. Muddaiah A, Zaffarullah W, Tewary A. Recurrent well-differentiated liposarcoma of the larynx: a case report and review of literature. Eur Arch Otorhinolaryngol. 2010;267(7):1163-5.

23. Mestre de Juan MJ, Fernondez-Acecero MJ. Laryngeal liposarcoma: report of a case. Pathol Res Pract. 1999;195(2):125-8.
24. Brauchle RW, Farhood AI, Pereira KD. Welldifferentiated liposarcoma of the epiglottis. J Laryngol Otol. 2001;115(7):593-5.

25. Fahmy FF, Osborne J, Khalil HS, Rodgers B. Well-differentiated liposarcoma of the hypopharynx. J Laryngol Otol. 1998;112(9):8802.

26. Powitzky R, Powitzky ES, Garcia R. Liposarcoma of the larynx. Ann Otol Rhinol Laryngol. 2007;116(6):418-24.

27. Wambeek ND, Mendelson RM. Liposarcoma of the hypopharynx. Australas Radiol. 1996;40(2):165-8.

28. Mouret P. Liposarcoma of the hypopharynx. A case report and review of the literature. Rev Laryngol Ftol Rhinol. 1999;120(1):39-42.

29. Nouri H, Hassani R, Aderdour L, Raji A. The welldifferentiated liposarcoma of the hypopharynx. Eur Ann Otorhinolaryngol Head Neck Dis. 2011;128(3):143-145.

30. Sotirović J, Vukomanović-Djurdjević B, Baletić N, Pavićević L, Bijelić D, Perić A. Recurrent lipomatous tumor of hypopharynx: case report and literature review. Acta Clin Croat. 2014; 53:365368.

31. Nishihoria T, Aokia M, Aokia K, Yamadaa N, Bunyaa K, Mizutaa K, et al. The surgical treatment for recurrent liposarcoma of the hypopharynx in a pregnant woman. J Med Cases. 2011;2(3):127-31.

32. Hurtado JF, Lopez JJ, Aranda FI, Talavera J. Primary liposarcoma of the larynx. Case report and literature review. Ann Otol Rhinol Laryngol. 1994;103(4):315-8.

33. Reed JM, Vick EG. Hypopharyngeal liposarcoma. Otolaryngol Head Neck Surg. 1996;114(3):499500.

34. Meis JM, Mackay B, Goepfert H. Liposarcoma of the larynx. Case report and literature review. Arch Otolaryngol Head Neck Surg. 1986;112(12):1289-92.

35. Allsbrook WC Jr, Harmon JD, Chongchitnant N, Erwin S. Liposarcoma of the larynx. Arch Pathol Lab Med. 1985;109(3):294-6.

36. Takano K, Kondoh A, Matsumiya H, Himi T. A well-differentiated liposarcoma of the hypopharynx. Otolaryngol Head Neck Surg. 2011;144(3):479-80.

37. Miettinen M. Atypical lipomatous tumor and liposarcomas. In: Miettinen $\mathrm{M}$, editor. Modern soft tissue pathology: tumors and non-neoplastic conditions. New York (NY): Cambridge University Press; 2010. p. 432-60. 